\title{
Antimicrobial metabolite profiling of Nigrospora sphaerica from Adiantum philippense L.
}

Kolathuru Puttamadaiah Ramesha, Nagabhushana Chandra Mohana, Bettadapura Rameshgowda Nuthan, Devaraju Rakshith and Sreedharamurthy Satish ${ }^{*}$ (D)

\begin{abstract}
Background: Endophyte bestows beneficial aspects to its inhabiting host, along with a contribution to diverse structural attributes with biological potential. In this regard, antimicrobial profiling of fungal endophytes from medicinal plant Adiantum philippense revealed bioactive Nigrospora sphaerica from the leaf segment. Chemical and biological profiling through TLC-bioautography and hyphenated spectroscopic techniques confirmed the presence of phomalactone as an antimicrobial metabolite.

Results: The chemical investigation of the broth extract by bioassay-guided fractionation confirmed phomalactone as a bioactive antimicrobial secondary metabolite. The antimicrobial activity of phomalactone was found to be highest against Escherichia coli by disc diffusion assay. The MIC was found to be significant against both Escherichia coli and Xanthomonas campestris in the case of bacteria and dermatophyte Candida albicans at $150 \mathrm{\mu g} / \mathrm{ml}$, respectively.

Conclusions: Overall, the results highlighted the antimicrobial potential of phomalactone from the endophyte Nigrospora sphaerica exhibiting a broad spectrum of antimicrobial activity against human and phytopathogenic bacteria and fungi. This work is the first report regarding the antibacterial activity of phomalactone.
\end{abstract}

Keywords: Adiantum philippense, Nigrospora sphaerica, Phomalactone, Antimicrobial activity, TLC-bioautography

\section{Background}

Endophytes such as bacteria, fungi, and actinomycetes inhabit healthy plant tissues and have a crucial role in the defense mechanism of the host against pathogens, herbivores, and abiotic stresses $[27,35]$. Until the previous decade, research on endophytic microbes was confined only to diversity and distribution. However, a new avenue was envisioned because of taxol from Taxomyces andreanae inhabiting Taxus brevifolia [18, 26].

Natural products from endophytes have gained wide attention from the research community due to their wide structural diversities with potential biological applications.

\footnotetext{
* Correspondence: satish.micro@gmail.com
}

Microbial Drug Technological Laboratory, Department of Studies in

Microbiology, University of Mysore, Manasagangotri, Mysore, Karnataka 570006, India
However, the quest for chemical diversity attributed to secondary metabolites from endophytes has been led to an increased number of redundancies; making it laborious for natural product researchers for confining new analogs with potent biological activities [16, 24].

The genus Nigrospora has been reported previously to produce bioactives viz., nigrosporolides, phomalactone [8, 10], nigrosporins [17], lactones, epoxydons [29], diterpenes, diketopiperazines, lactones [25], nigrosporolides, and pyrones. The plant source Adiantum philippense L. is commonly known as "Hanspadi" or "Strolling Maidenhair plant." A. philippense has been traditionally used numerous parts of India as an ethnomedicinal as well as the cosmetic plant [21]. The ethnomedicinal aspects include the treatment of illnesses, consuming sensation, erysipelas, epileptic fits, looseness of the bowels, 
bronchitis, coughing, and elephantiasis [2]. Earlier reports have stated the potential capacity of the plant exhibiting antibacterial and antifungal activities.

The present investigation emphasizes the identification of endophytic fungus $N$. sphaerica inhabiting A. philippense, and bioactivity-guided dereplication process led to the isolation of a potent antimicrobial agent phomalactone. To the best of our knowledge, this is the first report elaborating the antibacterial activity of phomalactone.

\section{Methods}

\section{Materials}

Potato dextrose agar (PDA) and broth (PDB), MuellerHinton agar (MHA) and broth (MHB), Sabouraud dextrose agar (SDA), gentamicin, nystatin, and sodium dodecyl sulfate (SDS) were purchased from HiMedia (Mumbai, India). Other materials were obtained from different manufacturers such as sodium hypochlorite solution (available chlorine 4\%) from Fisher Scientific (Mumbai, India); Precoated aluminum-backed TLC silica gel plates $\left(60 \mathrm{~F}_{254}\right)$ from Merck (Darmstadt, Germany); HPLC grade solvents like ethyl acetate; hexane and methanol from SDFCL (Mumbai, India); and Silica gel 60-120 mesh from Qualigens (Mumbai, India). The ITS 1 and ITS 4 primers, 2,3,5-triphenyl tetrazolium chloride (TTC), and Thiazolyl Blue Tetrazolium Bromide (MTT) were procured from Sigma-Aldrich (Missouri, USA).

\section{Test organisms}

All the test microbial pathogens such as Staphylococcus aureus (MTCC 7443), Bacillus subtilis (MTCC 121), Bacillus cereus (MTCC 430), Staphylococcus epidermidis (MTCC 435), Escherichia coli (MTCC 7410), Klebsiella pneumonia (MTCC 7407), Salmonella typhi (MTCC 733), Shigella flexneri (MTCC 1457), Vibrio parahaemolyticus ((MTCC 451), Xanthomonas campestris (MTCC 7908), and Candida albicans (MTCC 183) were procured from Microbial Type Culture Collection and Gene Bank (MTCC; Chandigarh, India).

\section{Plant collection and isolation of fungal endophytes}

Healthy asymptomatic $A$. philippense was collected from the Western Ghats region near Virajpete $\left(12.2^{\circ} \mathrm{N}, 75.8^{\circ} \mathrm{E}\right)$. The plant specimen was identified by Dr. S. Mahadevakumar (field taxonomist) and submitted to herbarium (Voucher specimen number: UOM-BOT20-AP02). The plant material was sealed in sterile polythene bags and transported to the $\mathrm{lab}$ and processed within $8 \mathrm{~h}$ of collection. The plant material was initially washed under tap water for removing unwanted debris and soil; followed by sterile double distilled water $(\mathrm{Dw})$ washes for twice. The plant leaf material was separated and cut into segments of $0.5 \mathrm{~cm}^{2}$ size. The plant segments were subjected to surface sterilization with $75 \%$ $(v / v)$ ethanol $(1 \mathrm{~min})$, followed by $4 \%(v / v) \mathrm{NaOCl}(4 \mathrm{~min})$ and $75 \%(v / v)$ ethanol (1 min). Finally, tissue bits were rinsed with sterile double distilled water to remove residual surface sterilizing agents and blot dried under aseptic conditions. The surface-sterilized and blot dried leaf segments were placed on potato dextrose agar amended with antibiotic chloramphenicol $(100 \mathrm{mg} / \mathrm{L})$ to eliminate bacterial growth followed by incubation in a light chamber for two weeks at a 12-h light/dark cycles at $25 \pm 2{ }^{\circ} \mathrm{C}$. The fungal colonies were picked and transferred onto fresh potato dextrose agar plates devoid of any antibiotics [15, 23].

\section{Genomic DNA extraction}

Bioactive mycoendophyte N. sphaerica isolated from $A$. philippense was cultured in potato dextrose broth for a week at $25 \pm 2{ }^{\circ} \mathrm{C}$ for isolation of genomic DNA. The mycelial mat was harvested, grounded, and transferred to a microcentrifuge tube containing $1 \mathrm{ml}$ of $2 \times \mathrm{CTAB}$ extraction buffer and incubated at $65^{\circ} \mathrm{C}$ water bath for $30 \mathrm{~min}$, later centrifuged at $10,000 \mathrm{~g}(10 \mathrm{~min}$; RT). The aqueous phase was mixed with equal volume phenol: chloroform: isoamyl alcohol (25:24:1) for total DNA extraction followed by the addition of propanol to precipitate DNA [9].

\section{Polymerase chain reaction amplification}

The PCR amplification was performed according to the protocol of White et al. [31] using ITS1 and ITS4 set of universal primers. The PCR reaction mixture $(50 \mu \mathrm{L})$ was prepared with $5 \mu \mathrm{L}$ PCR buffer (10X; $15 \mathrm{mM} \mathrm{MgCl}_{2}$ ), $5 \mu \mathrm{L}$ of dNTPs $(2 \mathrm{mM}), 2 \mu \mathrm{L}$ of forward and reverse primers $(5$ pmole $/ \mu \mathrm{L}), 2 \mu \mathrm{L}$ Taq polymerase $(1 \mathrm{U} / \mu \mathrm{L})$, and the final volume was made up for $50 \mu \mathrm{L}$ using Nanopure water $(30 \mu \mathrm{L})$. The PCR reaction was carried out for $30 \mathrm{cy}$ cles with the following conditions denaturation $94^{\circ} \mathrm{C}(40 \mathrm{~s})$, annealing at $54^{\circ} \mathrm{C}(60 \mathrm{~s})$, extension at $72{ }^{\circ} \mathrm{C}(60 \mathrm{~s})$, and final extension for a 10 -min interval at $72{ }^{\circ} \mathrm{C}$. The sequence was analyzed using $\mathrm{ABI} 3730$ sequencer.

\section{Antimicrobial screening by agar plug method}

The pure cultures of fungal endophytes isolated from $A$. philippense were preliminarily screened for antimicrobial activity using the agar plug diffusion method. Pure cultures of fungal endophytes were cultured in potato dextrose agar for 21 days at $25 \pm 2{ }^{\circ} \mathrm{C}$. The agar plugs of pure cultures were placed onto Mueller-Hinton agar preseeded with test organisms, followed by refrigeration at $4{ }^{\circ} \mathrm{C}$ for $1 \mathrm{~h}$ to facilitate diffusion of metabolites, and further plates were incubated at $37 \pm$ $2{ }^{\circ} \mathrm{C}(24 \mathrm{~h})$ for bacteria and $25 \pm 2{ }^{\circ} \mathrm{C}(72 \mathrm{~h})$ for fungi. After incubation, zones of inhibition around the agar plug were observed [37]. 


\section{Fermentation and extraction of secondary metabolites}

Bioactive $N$. sphaerica was cultured in $2 \mathrm{~L}$ Erlenmeyer flasks (10) containing $450 \mathrm{ml}$ potato dextrose broth at $25 \pm 2{ }^{\circ} \mathrm{C}$ for 4 weeks under static conditions. The culture broth was filtered, and the liquid supernatant was extracted thrice with an equal volume of ethyl acetate and concentrated using a rotary flash evaporator (Rotavapor $\mathrm{R}^{\circ} \mathrm{R}-3$, Buchi) $\left(50^{\circ} \mathrm{C}\right)$ and it was stored at $4{ }^{\circ} \mathrm{C}$. The ethyl acetate extract concentrate was fractionated by column chromatography over a silica gel column (50 g, 60-120 mesh) using stepwise gradient elution from hexane: ethyl acetate (100:0 to 0:100) mixtures with increasing polarity, to afford different fractions (eluates). The fractions obtained were developed in TLC for pooling the similar fractions using optimized solvent system ethyl acetate: hexane $(1: 1 ; v / v)[22]$.

\section{Detection of antimicrobial metabolite by TLC- bioautographic assay}

Analytical TLC was employed for detecting antimicrobial metabolites. Ten microliters of flash evaporated ethyl acetate fraction of bioactive mycoendophyte $N$. sphaerica was spotted on TLC silica gel plates and developed in an optimized solvent system of ethyl acetate/ hexane $(1: 1 ; v / v)$. TLC sheets were observed under UV light $(254 \mathrm{~nm})$ and dried in aseptic conditions. The developed TLC sheets were placed onto sterile Petri plates and overlaid with Mueller-Hinton agar amended with TTC $(1 \mathrm{mg} / \mathrm{ml})$ for bacteria and Sabouraud Dextrose agar for fungi previously seeded with $1 \%$ standardized (McFarland standard) microbial inoculum and incubated. After incubation, for fungi, the Petri plate was flooded with $10 \mathrm{ml}$ of soft agar (agar 1\% w/v) amended with MTT $(0.05 \% w / v)$. Inhibition zones were observed as clear spots, and the active bands and corresponding retention factor $\left(R_{f}\right)$ value was measured $[19,23]$.

\section{Antimicrobial activity by disc diffusion method}

The disc diffusion method was used to determine the antimicrobial activity of the endophytic fungal extract. Sterile media plates (MHA for bacteria and SDA for fungi) were seeded with predetermined test microbial inocula as described by Rakshith et al. [22]. Sterile discs were impregnated with purified bioactive metabolites from the stock solution $(10 \mathrm{mg} / \mathrm{ml})$. The concentration of $30,60,150,300,450$, and $600 \mu \mathrm{gdisc}^{-1}$ were placed on respective agar media with gentamicin $(10 \mu \mathrm{g} / \mathrm{disc}$; for bacteria) and nystatin (100 U/disc; for fungi) as a positive control, whereas ethyl acetate served as a negative control. Inoculated plates were incubated at $37 \pm 2{ }^{\circ} \mathrm{C}(24 \mathrm{~h})$ for bacteria and $25^{\circ} \mathrm{C} \pm 2(72 \mathrm{~h})$ fungi. After the incubation, the zone of inhibition was measured around discs in millimeter and results were expressed as mean $\pm \mathrm{SD}$.

\section{Spectral measurements}

HPLC profiling The purity of the bioactive metabolite was analyzed with reference to the chromatogram of the crude ethyl acetate extract of $N$. sphaerica with Shimadzu UFLC - LC - 20 AD series. An amenable $5 \mu \mathrm{m} \mathrm{C18} 120 \AA ̊ 2250 \times 4.6 \mathrm{~mm}$ LC (A8-ST5C18G12098) column was used for the detection of metabolites. The injection volume of $20 \mu \mathrm{L}(1 \mathrm{mg} / \mathrm{ml})$ was developed with the mobile phase using methanol with a flow rate of $1 \mathrm{ml} / \mathrm{min}$. The chromatogram was recorded at $260 \mathrm{~nm}$ using Lab solutions (Shimadzu corp., Japan) software.

LC-MS The mass of the purified bioactive metabolite was measured using liquid chromatography coupled with Q-TOF in positive electrospray ionization-mass spectrometry (Waters Acquity UPLC Synapt G2 HDMS) with BDS HYPERSIL C18 column $(250 \times 4.6 \mathrm{~mm} \times$ $5 \mu \mathrm{m})$. The LC separation was recorded using Quattro Premier XE with the Mass Lynx 4.1 software with a gradient solvent system A: $0.1 \mathrm{vol}$ \% formic acid-water and B: 0.1 vol. \% formic acid-acetonitrile; $2-98 \%$ B in 50.0 min of run time with a controlled column temperature at $30^{\circ} \mathrm{C}$. The Q-TOF-ESI-MS data were recorded in the range of 200 and $400 \mathrm{~nm}$ and positive ESI full MS (60.00-1000.00).

NMR The ${ }^{1} \mathrm{H}$ and ${ }^{13} \mathrm{C}$ NMR spectra of the purified bioactive metabolite $(35 \mathrm{mg} / \mathrm{ml})$ were recorded using deuterated chloroform $\left(\mathrm{d}-\mathrm{CDCl}_{3}\right)$ on an Agilent $400-\mathrm{MHz}$ WB (Widerbore) NMR magnet (Santa Clara CA, USA) spectrometer using the VJ3.1 software at $400 \mathrm{MHz}$ and $100 \mathrm{MHz}$, respectively.

FT-IR Fourier transform infrared spectra of the bioactive purified fraction $(1 \mu \mathrm{Lof} 1 \mathrm{mg} / \mathrm{ml})$ was recorded using PerkinElmer spectrum TwoTM ATR MIRacle Diamond S2PE (Norwalk, CT, USA) spectrophotometer with the scanning range of $4000-600 \mathrm{~cm}^{-1}$.

\section{Determination of minimal inhibitory concentration}

The MIC was determined by the microdilution method according to Clinical and Laboratory Standards Institute (CLSI) by modifications by [23]. Briefly, the stock solutions of purified phomalactone $(10 \mathrm{mg} / \mathrm{ml})$, Gentamicin, and Nystatin $(2 \mathrm{mg} / \mathrm{ml})$ were prepared. Two-fold dilutions were carried out in the concentration range of $100-0.19 \mu \mathrm{g} / \mathrm{ml}$, in $100 \mu \mathrm{L}$ of sterile Mueller Hinton broth for bacteria and Sabouraud's dextrose broth for fungi. Twenty microliters of standard suspension of bacterial and fungal inocula were added, except for sterility control well. Gentamicin for bacteria and Nystatin for fungi used as a standard positive control along with growth and sterility controls. Minimal inhibitory 
concentrations were determined by absorbance at 600 $\mathrm{nm}$ after incubation with compounds at $37 \pm 2{ }^{\circ} \mathrm{C}(24 \mathrm{~h})$ for bacteria and $25^{\circ} \mathrm{C} \pm 2$ (72 h) fungi [15].

\section{Statistical analysis}

All the experiments were conducted in triplicates and statistical significance such as one-way ANOVA was evaluated using IBM SPSS (Version 25) software.

\section{Results}

Isolation and identification of endophytic fungi Nigrospora sphaerica

In the present study, bioactive mycoendophyte isolated from the surface-sterilized leaves of $A$. philippense was subjected to morphological, microscopic (Fig. 1), and molecular identification. Based on ITS rDNA gene sequencing, it was identified as $N$. sphaerica and submitted to GenBank (Accession number: MF400860).

\section{Phylogenetic affiliation}

The amplified sequenced results were processed using Mega X software for assigning putative identity and for assigning OTU's based similarity. Followed by a neighborjoining algorithm with a bootstrap value of 1000 for assigning phylogenetic affiliation (Fig. 2).

\section{Antimicrobial activity of ethyl acetate extract $N$. sphaerica} The antimicrobial activity of phomalactone from $N$. sphaerica was determined by the disc diffusion assay against a panel of test pathogenic microorganisms. The bioactive compound exhibited an excellent zone of inhibition against all the test microbial pathogens in an increasing order. The antimicrobial activity was found to be highest against $E$. coli with a $24.33 \mathrm{~mm}$ diameter followed S. typhi $(22.67 \mathrm{~mm})$, B. cereus $(21.67 \mathrm{~mm}), S$. aureus $(19 \mathrm{~mm}), K$. pneumonia $(18.67 \mathrm{~mm})$, B. subtilis (17.67 mm), X. campestris $(17.67 \mathrm{~mm})$, V. parahaemolyticus $(16.67 \mathrm{~mm})$, and $S$. epidermidis $(12.67 \mathrm{~mm})$ at $30 \mu \operatorname{gdisc}^{-1}$ concentration. The metabolite was effective against Candida albicans at a higher concentration of $150 \mu \mathrm{g}$ (Fig. 3, Table 1).

\section{TLC-bioautography assay}

Metabolite with antimicrobial activity was identified as a clear zone against a red background on Mueller-Hinton agar plates and a dark blue background on the Sabouraud Dextrose agar plate. The zone of inhibition was observed at a $R_{f}=4.5$ indicating the purified bioactive metabolite from the ethyl acetate extract of $N$. sphaerica (Fig. 4).

\section{Spectral data}

Color: Yellow

Physical state: Amorphous Semi-Solid

Yield: $0.45 \mathrm{~g} / \mathrm{L}$

Name: Phomalactone [(5R, 6R)-5 hydroxy-6-[(E)prop-1-en-1-yl]-5, 6-dihydroxy-2 h-pyran-2-one].

HPLC: The purified compound eluted at RT-4.89 with 86\% purity (Supplementary Figure 1).

LCMS: 155.126 (positive mode) (Supplementary Figure 2) NMR:

${ }^{1}$ H NMR: (400 MHz, $\left.\mathrm{CDCl}_{3}-\mathrm{d} 6, \boldsymbol{\gamma}, \mathrm{ppm}\right): 2.05$ (s, 3H), $2.80(\mathrm{~s}, 1 \mathrm{H},-\mathrm{OH}), 4.53(\mathrm{~m}, 1 \mathrm{H}), 4.76(\mathrm{~m}, 1 \mathrm{H}) 5.67-5.69$ (dd, or q, 2H), 6.03-6.04 (m, 2H) (Supplementary Figure 3).

${ }^{13} \mathrm{C}$ NMR: $\left(100 \mathrm{MHz}, \mathrm{CDCl}_{3}-\mathrm{d} 6\right.$,, $\left.\mathrm{ppm}\right): 17.6(\mathrm{C}-9)$, 63.8 (C-5), 122.3 (C-3), 132.7 (C-8), 144.8 (C-4), 162.1 (C-2, C-0), 83.3 (C-6), 123.5 (C-7). MS (ESI, m/z): 154.06, $(100 \%), 155.07(\mathrm{M}+1)$ (Supplementary Figure 4).

FT-IR: $\quad 3600-3200$ (S, $-\mathrm{OH}$ stretch), $1750-1720$ (ether), 1680-1600 (alkene), 1448 ( $\mathrm{CH}_{3}$-bond), 10501150 (> C=O (1160) stretch), 1380 (-CH-bond) (Supplementary Figure 5).

The compound obtained was in the form of a yellow amorphous semi-solid with a molecular mass of 155.07 in ESI-positive mode. The ${ }^{1} \mathrm{H}$ NMR spectrum revealed the presence of a secondary methyl group attached to carbon 5 in the compound. The ${ }^{13} \mathrm{C}$ NMR revealed 8 carbon signals: signals for one quaternary carbon atoms,

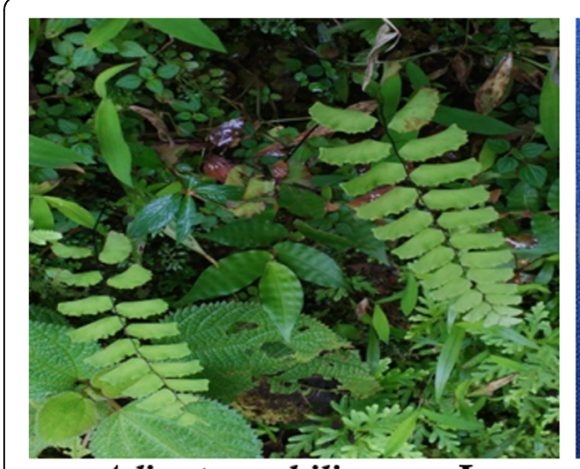

Adiantum philippense $\mathrm{L}$.

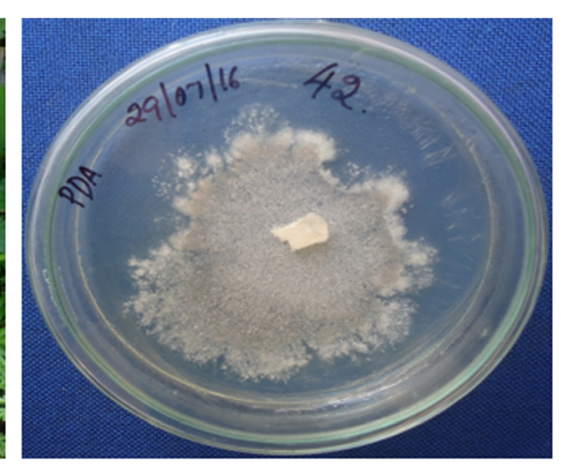

Nigrospora sphaerica

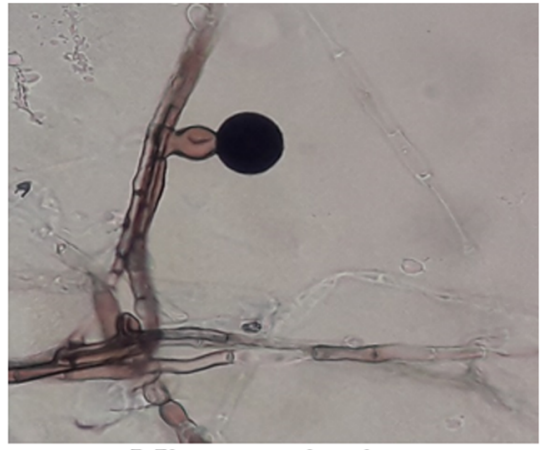

Microscopic view

Fig. 1 Plant specimen, morphology, and microscopy of Nigrospora sphaerica 


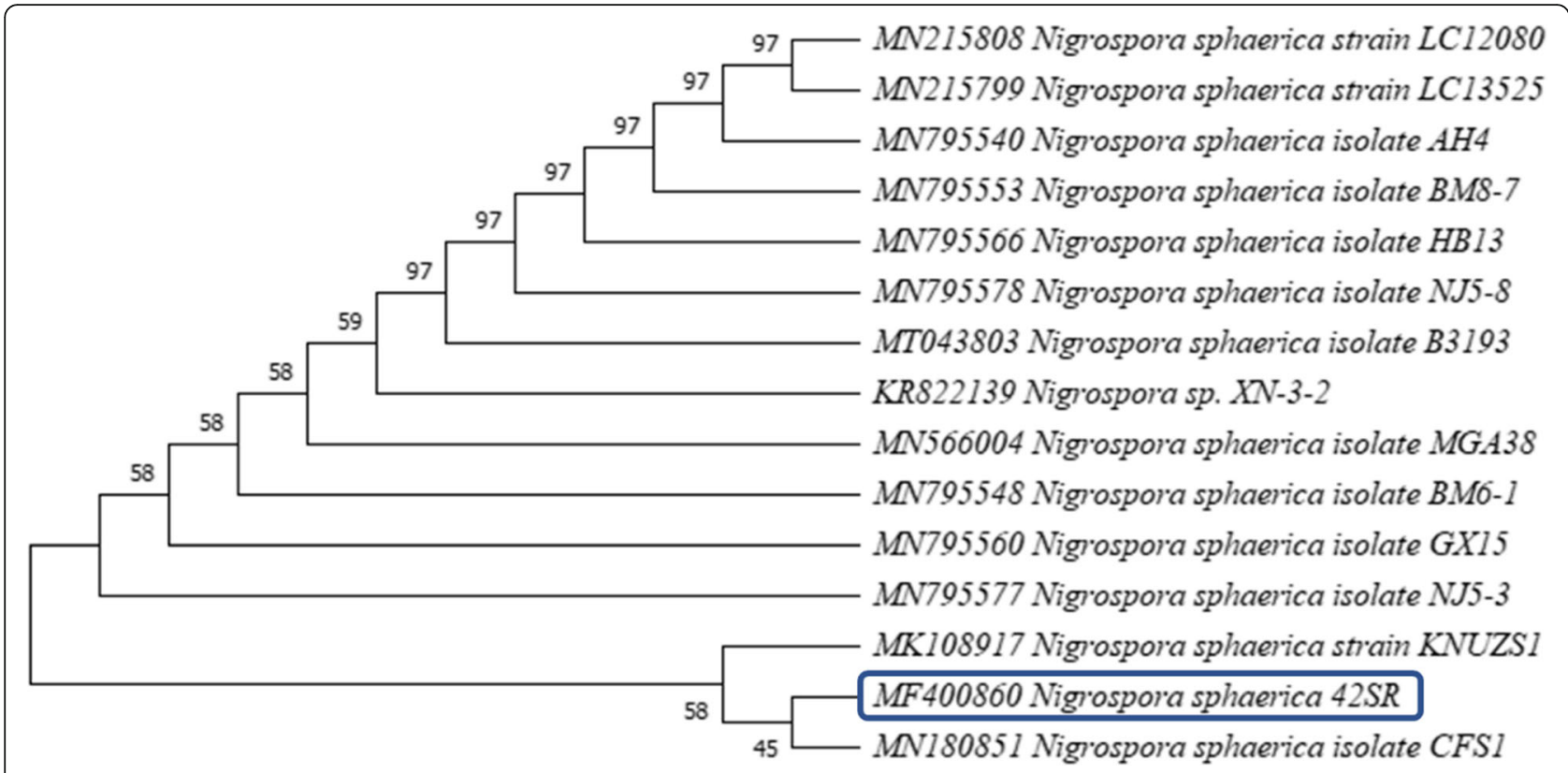

Fig. 2 Phylogenetic tree derived from neighbor-joining analysis showing the evolutionary relationship using the MEGA-X software

6 methane groups, and one methyl group representing dihydropyranon chemical skeleton. The presence of the hydroxyl group at $3600-3200 \mathrm{~cm}^{-1}$ and carbonyl at 1160 $\mathrm{cm}^{-1}$ confirmed the bioactive to be phomalactone.

\section{Minimal inhibitory concentration}

The MIC was found to be lowest against E. coli and $X$. campestris at $3.12 \mu \mathrm{g}$ concentration followed by S. typhi, B. subtilis, B. cereus, and K. pneumonia at $6.25 \mu \mathrm{g}$. The inhibition was observed at $12.5 \mu \mathrm{g}$ for S. aureus, S. epidermidis, and C. albicans (Table 1). The results obtained indicated that Gram-negative bacteria were found to be more susceptible when compared to Gram-positive.

\section{Discussions}

Nigrospora sphaerica has also been reported from a vast range of host viz., Ginkgo biloba [20], Moringa oleifera [38], Phoenix dactylifera [1] and Saccharum arundinaceum [36]. In this study, the secondary metabolites of $N$. sphaerica, extracted with ethyl acetate showed a significant antimicrobial activity against bacteria and fungus viz., S. aureus, B. subtilis, S. epidermidis, E. coli, K. pneumonia, P. aeruginosa, S. typhi, S. flexneri, X. campestris,

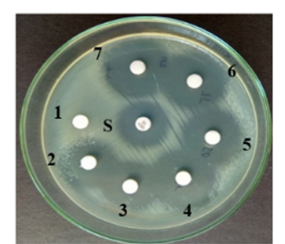

B. cereus

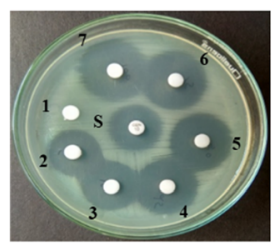

S. flexneri

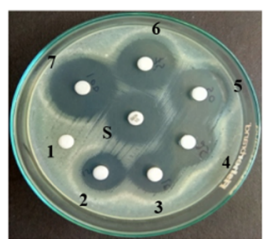

B. subtilis

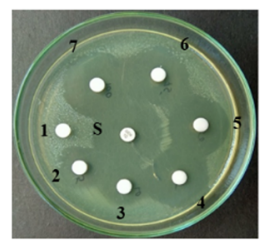

S. aureus

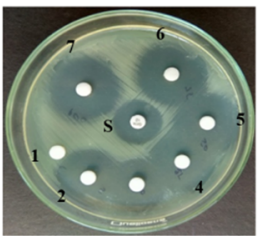

E. coli

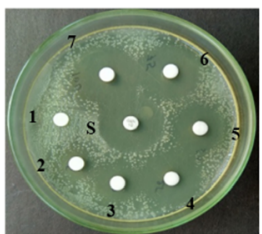

S. epidermidis

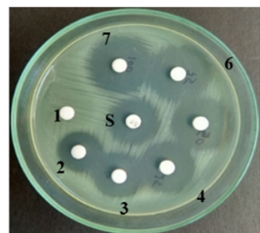

K. pneumonia

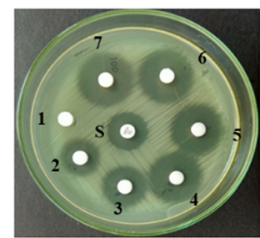

V. parahaemolyticus

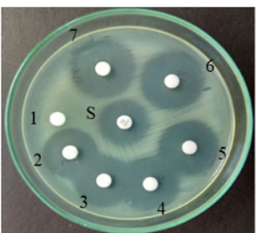

S. typhi

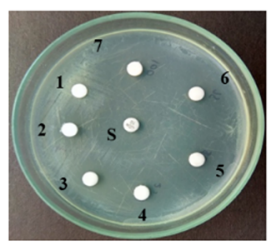

X. campestris

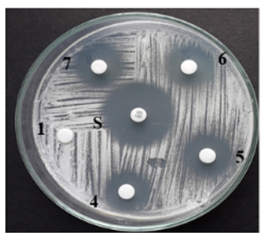

C. albicans

Fig. 3 Antimicrobial activity of phomalactone isolated from N. sphaerica. NOTE: Standard gentamicin (10 $\mu \mathrm{g}$ disc ${ }^{-1}$; for bacteria) and nystatin (100

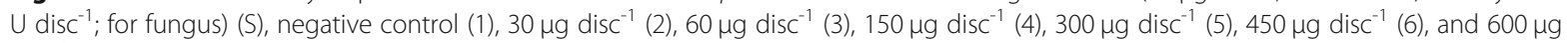
$\operatorname{disc}^{-1}(7)$ 


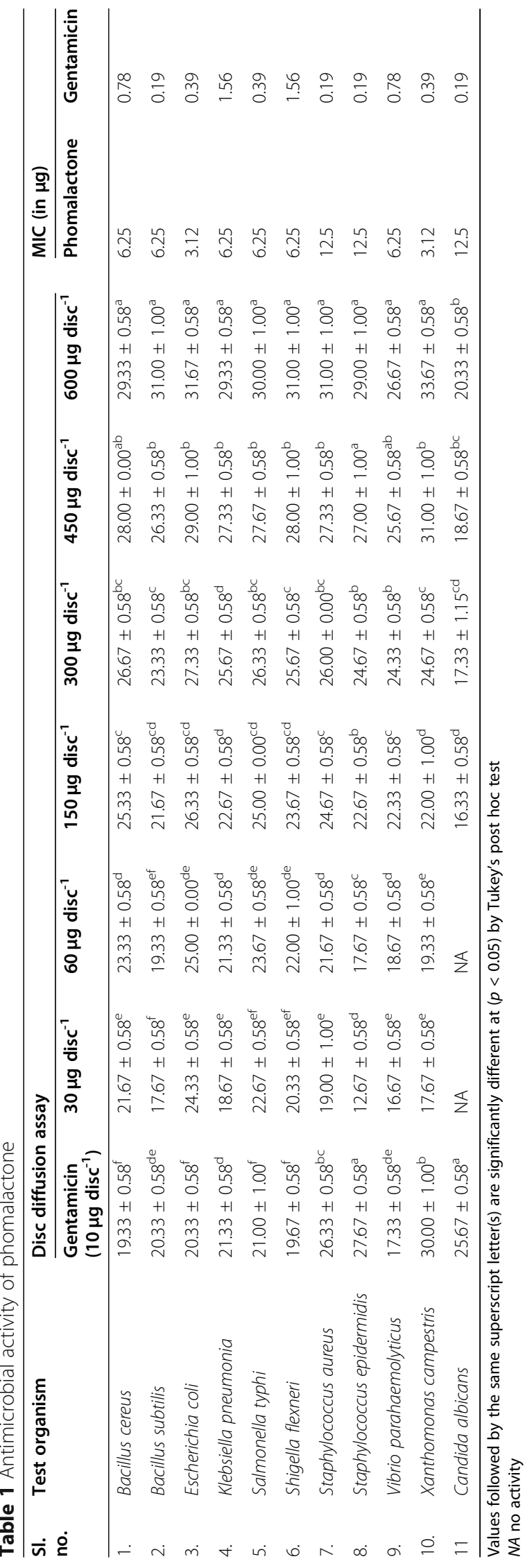




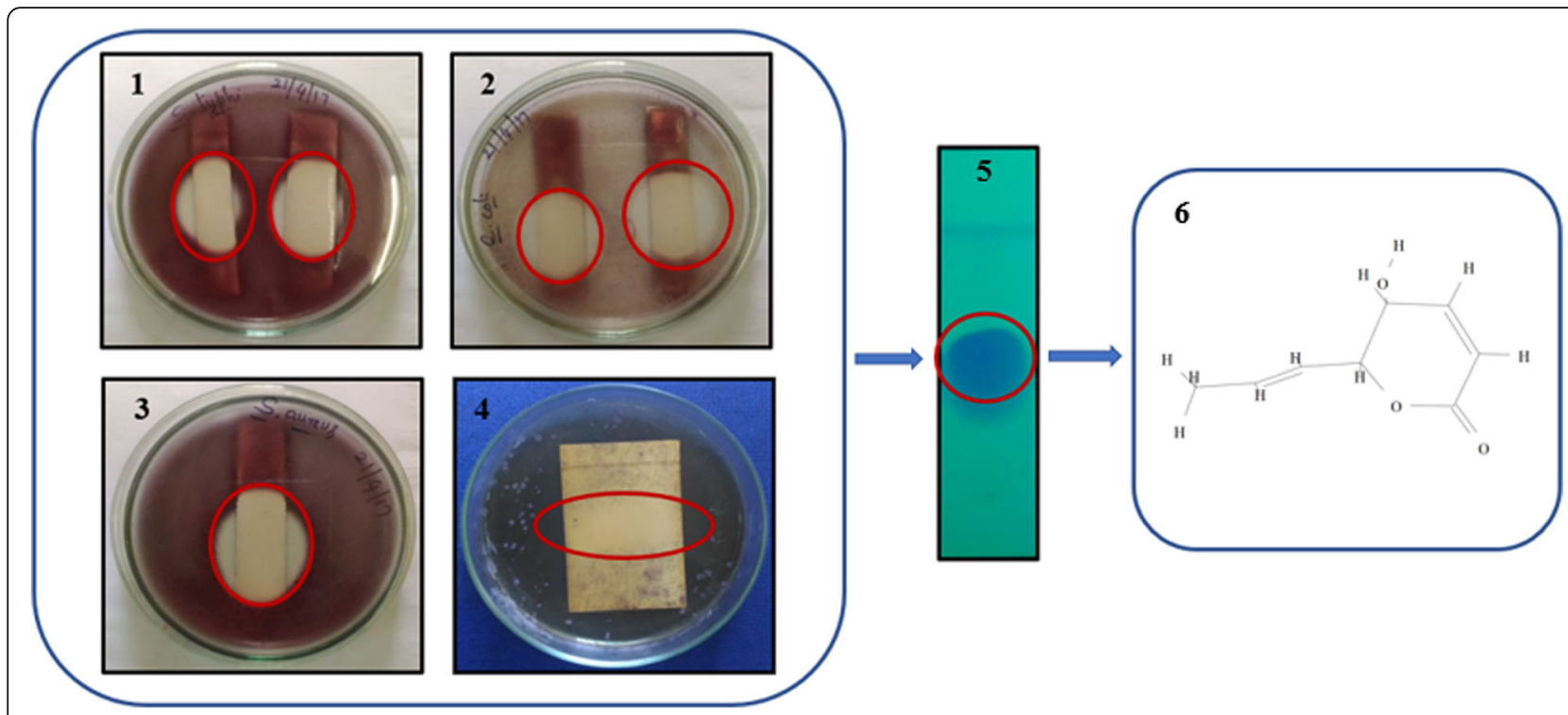

Fig. 4 TLC bioautography assay of purified phomalactone against selected microbial pathogens. (1) S. typhi, (2) E. coli, (3) S. aureus, (4) C. albicans, (5) TLC chromatogram (under UV light), and (6) structure of phomalactone

V. parahaemolyticus, and C. albicans, respectively. Several bioactive compounds have been reported from $N$. sphaerica which suggests the potential for discovery of pharmaceutically relevant substances. Previously, it was reported N. sphaerica to produce new antimicrobial bioactive secondary metabolites, such as nigrosporolides [5], nigrosporins [28], lactones [4], epoxydons and pyrones, diterpenes, diketopiperazines [3], and nigrosporolides [37].

Phomalactone is quite insecticidal [14] and has been isolated previously from several species of the fungal genera Nigrospora [30, 33], Xylaria [6], Aspergillus [11], Verticillium [7], Drechslera [13], Hirsutella (entomopathogenic) [12], Paecilomyces (entomopathogenic) [32], and Phoma [34]. Phomalactone has antifungal activity against Aspergillus fumigatus [11], nematocidal activity [7], immunomodulating activity [13], insecticide activity [12], and phytotoxic activity [4].

Phomalactone from endophyte Xylaria sp. exhibited to possess weak activity at $13 \mu \mathrm{g} / \mathrm{ml}$ against protozoan Plasmodium falciparum was reported by Carlos et al. 2008 . A study conducted by Kumudini et al. 2015 reported phomalactone from $N$. sphaerica had larvicidal, adulticide activity against Aedes aegypti and Anopheles quadrimaculatus mosquitoes with $\mathrm{LD}_{50}$ value $0.64 \mu \mathrm{g} / \mathrm{org}$ and $0.20 \mu \mathrm{g} / \mathrm{org}$, respectively. The investigation of biopotential endophytes inhabiting Zoysia japonica Steud by Kim et al. 2001 revealed phomalactone isolated from $N$. sphaerica exhibited potent fungitoxic activity against Phytophthora infestans and Phytophthora capsici. Its ecological role(s) in each of these species has not been rigorously studied, but its phytotoxic, fungitoxic, and insecticidal activities may be important to the various fungi that produce phomalactone.

\section{Conclusion}

In conclusion, this is the first report on the isolation of $N$. sphaerica from medicinal plant $A$. philippense. Chemical investigation through bioautography $N$. sphaerica displayed a broad spectrum of antimicrobial activity, which indicated that endophytic N. sphaerica as a potent producer of bioactive phomalactone derivative with great potential as a natural product drug molecule.

\section{Supplementary information}

Supplementary information accompanies this paper at https://doi.org/10 1186/s43141-020-00080-4.

Additional file 1: Supplementary Figure 1. HPLC analysis of purified bioactive compound phomalactone.

Additional file 2: Supplementary Figure 2. LCMS spectra of purified bioactive compound phomalactone.

Additional file 3: Supplementary Figure 3. Proton $\left({ }^{1} H\right)$ NMR Spectra of purified bioactive compound phomalactone.

Additional file 4: Supplementary Figure 4. ${ }^{13} \mathrm{C}$ NMR Spectra of purified bioactive compound phomalactone.

Additional file 5: Supplementary Figure 5. FT-IR Spectra of purified bioactive compound phomalactone.

\section{Abbreviations}

Dw: Distilled water; PDA: Potato dextrose agar; PDB: Potato dextrose broth; MHA: Mueller-Hinton Agar; TLC: Thin layer chromatography; TTC: 2,3,5Triphenyltetrazolium chloride; MTT: 1-(4,5-Dimethylthiazol-2-yl)-3,5diphenylformazan, Thiazolyl blue formazan; SDA: Sabouraud dextrose agar; MIC: Minimal inhibitory concentration 


\section{Acknowledgements}

The first author Ramesha K. P would like to thank UGC for providing Senior Research Fellowship, University Grants Commission Fellowship ID 201516RGNF-2015-17-SC-KAR-17538. The author Chandra Mohana. N would like to thank ICMR, New Delhi, for providing senior research fellowship (ICMR-SRF award No: 45/69/2018-PHA/BMS/OL). The author Nuthan B.R. would like to thank ICMR, New Delhi, for providing senior research fellowship (ICMR SRF Award No: OMI-Fellowship/23/2018-ECD-1). The authors are very thankful to the Institution of Excellence (IOE), University of Mysore; Department of Studies in Microbiology, University of Mysore, and Indian Institute of Science, Bengaluru, India, for providing instrumentation facilities.

\section{Authors' contributions}

RKP and SS designed the concept and prepared the manuscript; RKP executed the experiments and data analysis; NCM assisted in the experiment, data analysis, preparation of manuscript along with proof correction; and NBR and RD helped in proof correction. The authors have read and approved the manuscript.

\section{Funding}

Not applicable.

\section{Availability of data and materials}

The data from the study is publicly available.

\section{Ethics approval and consent to participate}

Not applicable.

\section{Consent for publication}

All the authors approve the manuscript for publication.

\section{Competing interests}

The authors declare there is no competing interests.

Received: 10 June 2020 Accepted: 24 September 2020

Published online: 22 October 2020

\section{References}

1. Abass MH, Hameed MA, Ahmed AN (2013) First report of Nigrospora sphaerica (Sacc.) Mason as a potential pathogen on date palm (Phoenix dactylifera L.). Can J Plant Pathol 35(1):75-80

2. Ali MS, Amin MR, Kamal CMl, Hossain MA (2013) In vitro antioxidant, cytotoxic, thrombolytic activities and phytochemical evaluation of methanol extract of the A. philippense L. leaves. Asian Pac J Trop Biomed 3(6):464-469

3. Cutler HG, Hoogsteen K, Littrell RH, Arison BH (1991) Epoxyexserohilone, a novel metabolite from Nigrospora sphaerica. Agric Biol Chem 55(8):2037-2042

4. Fukushima T, Tanaka M, Gohbara M, Fujimori T (1998) Phytotoxicity of three lactones from Nigrospora sacchari. Phytochemistry 48(4):625-630

5. Harwooda JS, Cutler HG, Jacyno JM (1995) Nigrosporolide, a plant growthinhibiting macrolide from the mould Nigrospora sphaerica. Nat Prod Lett 6(3):181-185

6. Jiménez-Romero C, Ortega-Barría E, Arnold AE, Cubilla-Rios L (2008) Activity against Plasmodium falciparum of lactones isolated from the endophytic fungus Xylaria sp. Pharm Biol 46(10-11):700-703

7. Khambay BPS, Bourne JM, Cameron S, Kerry BR, Zaki MJ (2000) A nematicidal metabolite from Verticillium chlamydosporium. Pest Manag Sci 56(12):1098-1099

8. Kim JC, Choi GJ, Park JH, Kim HT, Cho KY (2001a) Activity against plant pathogenic fungi of phomalactone isolated from Nigrospora sphaerica. Pest Manag Sci 57(6):554-559

9. Kim JS, Jun BK, Kim SH (2010) Simple and reliable DNA extraction method for the dark pigmented fungus, Cercospora sojina. Plant Pathol J 26(3):289-292

10. Kim J-C, Choi GJ, Park J-H, Kim HT, Cho KY (2001b) Activity against plant pathogenic fungi of phomalactone isolated from Nigrospora sphaerica. Pest Manag Sci 57(6):554-559

11. Komai SI, Hosoe T, Nozawa K, Okada K, De Campos Takaki GM, Fukushima K, Miyaji M, Horie Y, Kawai KI (2003) Antifungal activity of pyranone and furanone derivatives, isolated from Aspergillus sp. IFM51759, against Aspergillus fumigatus. Mycotoxins 53:11-17
12. Krasnoff SB, Gupta S (1994) Identification of the antibiotic phomalactone from the entomopathogenic fungus Hirsutella thompsonii var. synnematosa. J Chem Ecol 20(2):293-302

13. Krivobok S, Thomasson F, Seigle-Murandi F, Steiman R, Bottex-Gauthier C (1994) 6-Allyl-5,6-dihydro-5-hydroxypyran-2-one, a lactone produced by a new Drechslera species: specified $1 \mathrm{H}$ and 13C NMR assignments, mutagenic and immunomodulating testings. Pharmazie 49:605-607

14. Meepagala KM, Becnel JJ, Estep AS (2015) Phomalactone as the active constituent against mosquitoes from Nigrospora spherica. Agric Sci 6(10):1195

15. Mohana NC, Rao HCY, Rakshith D, Nuthan BR, Ramesha KP, Satish S (2020) Bioassay guided fractionation of bioactive metabolite from Corynascus verrucosus inhabiting Croton bonplandianus Baill. Process Biochem

16. Mohana NC, Rao HY, Rakshith D, Mithun PR, Nuthan BR, Satish S (2018) Omics based approach for biodiscovery of microbial natural products in antibiotic resistance era. J Genetic Eng Biotechnol 16(1):1-8

17. Murakami A (1970) NII-electronic library service. Chem Pharm Bull 2091

18. Naik S, Shaanker RU, Ravikanth G, Dayanandan S (2019) How and why do endophytes produce plant secondary metabolites? Symbiosis 78(3):193-201

19. Nuthan BR, Rakshith D, Marulasiddaswamy KM, Rao HCY, Ramesha KP, Mohana NC et al (2020) Application of optimized and validated agar overlay TLC-bioautography assay for detecting the antimicrobial metabolites of pharmaceutical interest. J Chromatogr Sci:1-10. https://doi.org/10.1093/ chromsci/bmaa045

20. Pawle G, Singh SK (2014) Antimicrobial, antioxidant activity and phytochemical analysis of an endophytic species of Nigrospora isolated from living fossil Ginkgo biloba. Curr Res Environ Appl Mycol 4(1):1-9

21. Périco $L L$, Rodrigues VP, de Almeida LFR, Fortuna-Perez AP, Vilegas W, Hiruma-Lima CA (2018) Maytenus ilicifolia Mart. Ex Reissek. In: Medicinal and aromatic plants of South America. Springer, Dordrecht, pp 323-335

22. Rakshith D, Gurudatt DM, Rao HCY, Mohana NC, Nuthan BR, Ramesha KP, Satish S (2020) Bioactivity-guided isolation of antimicrobial metabolite from Xylaria sp. Process Biochem 92:378-385

23. Rakshith D, Santosh P, Tarman K, Gurudatt D, Satish S (2013) Dereplication strategy for antimicrobial metabolite using thin-layer chromatographybioautography and LC-PDA-MS analysis. JPC J Planar Chromatograph Modern TLC 26(6):470-474

24. Ramesha KP, Mohana NC, Nuthan BR, Rakshith D, Satish S (2018) Epigenetic modulations of mycoendophytes for novel bioactive molecules. Biocatalysis Agricultural Biotechnol 16:663-668

25. Rukachaisirikul V, Khamthong N, Sukpondma Y, Phongpaichit S, HutadilokTowatana N, Graidist P, Kirtikara K (2010) Cyclohexene, diketopiperazine, lactone and phenol derivatives from the sea fan-derived fungi Nigrospora sp. PSU-F11 and PSU-F12. Arch Pharm Res 33(3):375-380

26. Strobel G, Daisy B (2003) Bioprospecting for microbial endophytes and their natural products. Microbiol Mol Biol Rev 67(4):491-502

27. Suryanarayanan TS, Thirunavukkarasu N, Govindarajulu MB, Sasse F, Jansen R, Murali TS (2009) Fungal endophytes and bioprospecting. Fungal Biol Rev 23(1-2):9-19

28. Tanaka M, Fukushima T, Tsujino Y, Fujimori T (1997) Nigrosporins a and $B$, new phytotoxic and antibacterial metabolites produced by a fungus Nigrospora oryzae. Biosci Biotechnol Biochem 61(11):1848-1852

29. Trisuwan K, Rukachaisirikul V, Sukpondma Y, Preedanon S, Phongpaichit S, Rungjindamai N, Sakayaroj J (2008) Epoxydons and a pyrone from the marine-derived fungus Nigrospora sp. PSU-F5. J Nat Prod 71(8): 1323-1326

30. Trisuwan K, Rukachaisirikul V, Sukpondma Y, Preedanon S, Phongpaichit S, Sakayaroj J (2009) Pyrone derivatives from the marine-derived fungus Nigrospora sp. PSU-F18. Phytochemistry 70(4):554-557

31. White TJ, Bruns T, Lee S, Taylor JW (1990) Amplification and direct sequencing of fungal genes for phylogeneticsin PCR protocols: a guide to methods and applications. In: Innis M, Gelfand DH, Sninsky JJ, White TJ (eds) Academic Press, San Diego, pp 315-322

32. Wu HY, Wang YL, Tan JL, Zhu CY, Li DX, Huang R, Niu XM (2012) Regulation of the growth of cotton bollworms by metabolites from an entomopathogenic fungus Paecilomyces cateniobliquus. J Agric Food Chem 60(22):5604-5608

33. Wu SH, Chen YW, Shao SC, Wang LD, Yu Y, Li ZY, Huang R (2009) Two new solanapyrone analogues from the endophytic fungus Nigrospora sp. YB-141 of Azadirachta indica. Chem Biodivers 6(1):79-85

34. Yamamoto I, Suide $H$, Hemmi T, Yamano T (1970) Antimicrobial a, Bunsaturated $\delta$-lactones from molds. Takeda Kenkyusho Ho 29(1):1-10 
35. Zhang HW, Song YC, Tan RX (2006) Biology and chemistry of endophytes. Nat Prod Rep 23(5):753-771

36. Zhang H, Deng Z, Guo Z, Tu X, Wang J, Zou K (2014) Pestalafuranones F-J, five new furanone analogues from the endophytic fungus Nigrospora $s p$. BM-2. Molecules 19(1):819-825

37. Zhang Y, Mu J, Feng Y, Kang Y, Zhang J, Gu PJ, Zhu YH (2009) Broadspectrum antimicrobial epiphytic and endophytic fungi from marine organisms: isolation, bioassay and taxonomy. Marine Drugs 7(2):97-112

38. Zhao JH, Zhang YL, Wang LW, Wang JY, Zhang CL (2012) Bioactive secondary metabolites from Nigrospora sp. LLGLM003, an endophytic fungus of the medicinal plant Moringa oleifera lam. World J Microbiol Biotechnol 28(5):2107-2112

\section{Publisher's Note}

Springer Nature remains neutral with regard to jurisdictional claims in published maps and institutional affiliations.

\section{Submit your manuscript to a SpringerOpen ${ }^{\odot}$ journal and benefit from:}

- Convenient online submission

- Rigorous peer review

- Open access: articles freely available online

High visibility within the field

- Retaining the copyright to your article

Submit your next manuscript at $\boldsymbol{\wedge}$ springeropen.com 